This is an electronic version of an article published in Esmonde, I. (2009). Explanations in mathematics classrooms: A discourse analysis. Canadian Journal of Science, Mathematics and Technology Education, 9(2), 86-99. Cognition and Instruction is available online at: www.tandfonline.com<http://www.tandfonline.com/> with http://www.informaworld.com/openurl?genre=article\&issn=1492-

$\underline{6156 \& \text { volume }=9 \& \text { issue }=2 \& \text { spage }=86}$

\title{
Explanations in mathematics classrooms: A discourse analysis
}

\author{
Indigo Esmonde \\ Ontario Institute for Studies in Education \\ University of Toronto
}

RUNNING HEAD: EXPLANATIONS 


\begin{abstract}
This paper focuses on student explanations as a discourse practice central to mathematics teaching and learning. I discuss classrooms as hybrid discourse spaces, and focus on how talk is used to accomplish social action. In doing so, I contrast several different social and sociomathematical norms for explanation, and suggest that students' choice of discourse practices position them within the classroom. Further, I caution educators against assuming that complete and detailed explanations are always best to support student learning. I discuss how explanations that are co-constructed by several students can actually support joint engagement in mathematical work and help peers stay 'on the same page' while avoiding hierarchical positioning.
\end{abstract}




\section{Explanations in mathematics classrooms: A discourse analysis}

Mathematics education research on student explanations has fallen into roughly

three kinds of studies: studies outlining what researchers consider to be characteristics of 'good' explanations (Andrews, 2005; Inglis, Mejia-Ramos, \& Simpson, 2007; Toulmin, 1958), studies outlining developmental trajectories through which individual students' or classroom sociomathematical norms for explanations develop (Hufferd-Ackles, Fuson, \& Sherin, 2004; Morgan, 1998; Webb \& Mastergeorge, 2003; Yackel \& Cobb, 1996), and studies examining the details of discourse practices to characterize what student explanations look and sound like (Morgan, 1998; Rowland, 1995). This focus on explanation in mathematical thinking has highlighted the special nature of mathematical explanations, and considered the difficulties students might face in developing proficiency in this discourse practice, but has focused primarily on the content of talk rather than its situated nature.

Only the last set of studies - characterizing explanations - has allowed any insight into the ways that explanations are used to position learners in relation to one another, and to accomplish other types of actions in social settings. As an example of how aspects of mathematical explanation serve to position explainers, Morgan (1998) discusses the features of written explanation that teachers value, such as a depersonalized tone, and shows how these values guide teachers' assessments of student mathematical understanding. 'More sophisticated' writing is equated with 'more sophisticated' mathematical understanding. Rowland (1995) demonstrates how in oral explanations, students use 'hedges' (such as about, around, maybe, probably) as "a 'Shield' against being "wrong"" (p. 350). These two examples demonstrate that explanations are used to 
position oneself, or others, in terms of mathematical understanding.

Rather than seeing student explanations as a transparent window through which to view their mathematical understanding, in this paper I consider how student explanations function as tools towards some goal within an interaction. Even if an overarching goal of mathematics instruction is to help people learn mathematical ways of acting and speaking, I will argue that we cannot achieve this goal without serious attention to how talk-in-interaction functions as a tool for social action. I will use vignettes taken from a larger empirical study to highlight the importance of this approach, and to suggest some of the analytic tools that can be useful to analyse talk as social action.

\section{What are explanations and why are they important?}

Many mathematics educators and teacher educators have come to see learning as a sociocultural process, in which learning mathematics is essentially learning to participate in a set of classroom mathematical discourse practices (Barwell, 2005; Sfard, 2001). Discourse practices that are associated with mathematics include conjecturing, supporting claims with evidence, representing mathematical concepts, and using all the specialized language and symbols of mathematics accurately (Moschkovich, 2002).

Explanation is one discourse practice that is central to mathematics teaching and learning. Mendez et al. (2007) argue that "presenting a logical warranted argument is a basic part of what it means to do mathematics" (p. 43). This position is supported by even a cursory examination of the Standards of the National Council of Teachers of Mathematics (2000). Two of the five Process Standards - communication, and reasoning and proof - are clearly heavily focused on student explanations. For the purposes of this paper, I consider a broad range of utterances under the heading 'explanation': utterances 
that are designed to 'explain why' (i.e., reasoning and proof), 'explain how' (i.e., outline a procedure), and 'explain your thinking.' This definition of explanations is admittedly broad, but accords with informal definitions in use in many classrooms, where the term 'explain' is used in a number of different ways.

Yackel and Cobb (1996) point out that "what counts as an acceptable mathematical explanation and justification is a sociomathematical norm" (p. 461) in the classroom, and these norms may change over time. Several classroom studies demonstrate that this process of change can occur over a short time (such as a single class period in Forman, McCormick, \& Donato, 1998) or longer-term (an academic year in Hufferd-Ackles et al., 2004), through concerted efforts by teachers to socialize students into their preferred discourse practices. The development of new (to the students) sociomathematical norms is not always simple or conflict-free, as students may resist adopting new norms for explanation or other aspects of classroom discourse practices (Herbel-Eisenmann, Lubienski, \& Id-Deen, 2006).

As Herbel-Eisenmann et al. demonstrate, students have agency and actively make choices about whether and how to participate in classroom talk; one danger of focusing only on norms in the classroom is that students who do not follow these norms can be positioned as 'not knowing' the norms. This may be the case for some students, especially those students whose familiar discourse practices are distant from the teacher's preferred practices. Still, other possibilities exist: students may be actively working against the norms, or using the norms strategically to position themselves within classroom activity. In other words, talk should be considered as a form of social action, rather than an unproblematic reflection of student thinking. A second danger of focusing 
on norms is that education researchers often place differential value on particular kinds of sociomathematical norms, and do not consider how a different set of norms might support student learning as effectively.

I will use the following vignettes as ways to highlight these two issues: how talk is used as social action, and how various forms of talk can support student learning. These vignettes were selected from a larger corpus of data because explanation was the central focus of the students' task, and because the two vignettes contrast in interesting ways. While I will not subject these vignettes to rigorous analysis, I will use them to elaborate on this approach to discourse analysis, and to consider the implications of this approach for mathematics education research more generally.

\section{Vignette 1}

It was a Friday afternoon in March, $4^{\text {th }}$ period, right after lunch. Only a few days remained before a written unit test, and the teacher, Ms. Delack, had organized a jigsaw activity (Clarke, 1994). In a jigsaw activity, each student in the class joins a group (that I will call 'jigsaw groups') to become an expert on a particular topic. These experts are then responsible for teaching their peers in other jigsaw groups about their topic. For their jigsaw, the class selected four topics that they considered difficult, and then split into four large groups, each large group responsible for one of the four difficult topics. Later, they would reconvene into their regular daily 'work groups' of 3-4 members, and each person would give a presentation on their topic.

The $4^{\text {th }}$ period class followed the Interactive Mathematics Program, Year 2 (known as IMP 2) curriculum, This textbook series combined the various strands of mathematics into an integrated course that focused on problem-solving, reasoning, and 
group collaboration around complex problems. IMP 2 is the equivalent, in the California system, to the Geometry course, typically taught in the $9^{\text {th }}$ or $10^{\text {th }}$ grade. This was one of three IMP 2 classes taught by Ms. Delack that were the focus of a larger study (Esmonde, 2006 , in press). The three classes were housed on the campus of a large, diverse urban high school (though the classes were officially part of several different programs within the school). The three classes were all diverse with respect to race, gender, prior achievement, and grade level (in each class, there were $9^{\text {th }}$ and $10^{\text {th }}$ grade students).

With about 15 minutes to work, a large group of 8 students gathered to discuss the feasible region. ${ }^{1}$ Several students immediately asserted that they already knew how to find the feasible region and seemed ready to end the discussion there, but one student, Riley, asked them, "right, but did you understand it? Can you explain it to your group?". He was the first in the group to articulate the idea that their task was to explain and not just understand the topic for themselves. Other group members seemed to agree with this articulation, and so the group focused on rehearsing explanations and answering one another's questions. Throughout the discussion, Riley took a leading role by asking other students to practice explaining. Most of the group members participated by contributing candidates for explanations, with Riley commenting on most of these contributions.

As an example of a typical interaction during this mathematical discussion, consider Excerpt 1. In this excerpt, Riley encourages another student, Garai, to explain his strategy. Riley then repeats and expands on Garai's strategy, and opens the discussion to further contributions from other group members. Transcript conventions include the following: numbers in subscript correspond to and index the onset of an action or gesture, 
the boundaries of overlapping talk are shown with square brackets at the beginning ( [ )

and end ( ] ) of the overlap, and elongated pronunciation is shown with a series of colons.

\section{Excerpt 1. Riley encourages Garai to explain his strategy}

\section{27:43 Riley Well Garai,}

2 27:44 Garai What

3 27:45 Riley How'd you find ${ }_{1}$ this $_{2}$ feasible region?

1. Taps Garai's paper with right hand

2. Right hand returns to his chin, gaze towards Garai

4 27:49 Garai $\quad{ }_{3}$ Well $_{4},(1.5$ second pause) I just plotted points, (inaudible) and see uh, which was true? For the problem, and (2 second pause) that's what I did

3. Gaze towards his paper

4. Leans back, gaze comes up towards Riley, hand comes up to his notebook

5 28:00 Riley $\quad{ }_{5}$ All right so you plot a point, and see, if it works

5. Gaze towards his own notebook

6 28:02 Garai Yeah

$7 \quad 28: 03$ Riley So like for each line 6 you plot a point above it?

And see if it works, and you plot a point below it, and see if it works? If it works then that means the line is going that way and you plot and you see where all the points, work.

6. Gaze comes up towards Garai; throughout, he gestures to his own notebook, emphasizing where points are plotted

8 28:14 Garai Yeah I see where all the points are and that's where the feasible region, where everything works at

9 28:19 Riley $\quad$ 7And- ((hear Candie laughing)) Anyone have any other ways?

\section{Gaze moves around the group}

$10 \quad 28: 27$ Kendra Wait what did he say? 8

8. Eye gaze directed to Riley

11 28:28 Riley He he, like they9

He would plot a point for ${ }_{10}$ this line, on ${ }_{11}$ this side of the line, and on ${ }_{12}$ this side of the line

(explanation continues for approximately 15 seconds)

9. Points with finger and pencil towards Kendra's paper

10. Points with finger and pencil to a line on Kendra's paper

11. Points with finger and pencil to one side of the line 


\section{Points with finger and pencil to the other side of the line}

This brief excerpt illustrates several key points about the group's interactions and the positioning of individual students. The group's work together was collaborative in that several students contributed ideas for consideration, and in that Riley and Garai actually co-constructed Garai's contribution to the group (see Riley's shaping of Garai's idea in turns 5 and 7). All students in the group were encouraged to come up with explanations, even after a correct explanation had been found (turn 9). As students worked together to co-construct and understand one another's explanations, these explanations became quite detailed (turns 7, 8 and 11). Explanations often made use of tools (such as the graphs each student had written in their notebooks) and conventions that the group had previously used.

In a later exchange after Garai had given his explanation, another student, Candie, told the group that she wasn't sure how to explain how to find the feasible region; she assured them that she understood the mathematics, but struggled with the explanation. Riley turned to Candie and asked her what she might say, and she began to rehearse an explanation. Just as Candie finished, and before the group had time to respond, the teacher called an end to the activity, and the students returned to their seats.

\section{Vignette 2}

Later that same afternoon, a group in Ms. Delack's $6^{\text {th }}$ period class was videotaped as they engaged in the same jigsaw activity. The four students in this vignette (Noreen, Daniel, Elly, and Lisbet) were assigned to discuss 'finding the highest profit,' the last step in solving a linear programming problem. ${ }^{2}$ 
Noreen, Elly and Lisbet began the discussion, with no active participation from Daniel. They displayed marked uncertainty about how to find the point of highest profit, as shown by comments like "I think... seventy-five and fifty or something," and "oh wait, not, not in here, maybe I'm wrong," (emphasis mine). Several possible strategies were suggested, but Noreen explained why she believed that the proposed alternatives would not work (though in fact, one of the suggestions was correct). After about three minutes of trying to work out an explanation, the group seemed to come to a tacit agreement that they could not solve this by themselves. For most of the rest of this activity, they talked amongst themselves about other matters - including their disapproval of the teacher's methods, which they said were unhelpful because, as Lisbet said, “you can’t like just figure out math.”

After a few minutes of this casual talk, Daniel sat up and looked around at his jigsaw group members for the first time since they began their discussion. He introduced the topic of the upcoming presentation he would have to give upon returning to his work group. The following excerpt demonstrates his request and the three other students' responses to his request are displayed in Excerpt 2.

\section{Excerpt 2. Daniel's request for help}

1 41:03 Daniel Okay $_{1}$ okay seriously. I- I- ${ }_{2}$ I don't know how to go about teaching my group this 3

1. Hits desk with right hand, begins to lean back in his chair

2. Shakes head as he speaks, gaze moves from person to person

3. Gaze rests on Noreen

2 41:09 Lisbet It doesn't matter.

3 41:10 Elly We already- We talked about it

$4 \quad 41: 12$ Noreen Basically you like go through all the other steps? and then 
you find like the ${ }_{4}$ highest profit line ${ }_{5}$ possible (inaudible) 6

4. Raises hand into the air

5. Pushes hand up emphasizing 'possible'

6. Lowers hand

5 41:20 Daniel What?

$6 \quad 41: 21$ Noreen ${ }_{7}$ Yeah.

7. Punctuates 'yeah' with gesture: closed fist moves towards Daniel, then drops back into her lap

When Daniel makes the statement that he doesn't know how he will teach his work group about this topic, his statement is taken as a request for help by his group members. This is evidenced by their responses: Lisbet (in turn 2) tells him that it doesn't matter that he doesn't know how to do it, Elly (in turn 3) chides him for not paying attention when the rest of the group discussed it, and Noreen (in turn 4) gives him a quick and very general explanation of a solution strategy - an explanation that omitted some critical details. When Daniel responded by acknowledging he did not understand her strategy, Noreen's response, 'yeah,' seemed to imply that she, too, was in the same boat. Earlier, Noreen had displayed and discussed a more solid understanding of the task than she shows in this instance, to Daniel. It appears that she chose to withhold information from Daniel, though we cannot know why.

The group returned to their desultory conversation about other matters, and waited for the teacher to come over. Several minutes later, at the very end of this activity, when the teacher was urging everyone to return to their seats, they managed to attract her attention. When the teacher arrived, Noreen immediately explained how to solve the problem, and Ms. Delack confirmed that Noreen was correct. Elly seemed unsatisfied, and asked the teacher how they could be sure which point provided the highest profit. 
The teacher gave a brief explanation on this point. The group then stood and each student returned to their own group.

\section{Analysing explanations: a focus on discourse}

In both vignettes, explanations were central to the group's engagement in mathematical discourse. Because one central goal of mathematics education is to support students' participation in mathematical discourse practice, it is valuable to analyse the sociomathematical norms for explanation which are evident in these interactions. As one approach to this type of analysis, I will briefly discuss three types of discourse markers that are often associated with formal mathematical explanations such as the presence or absence of personal pronouns (Morgan, 1998), a present-tense temporal structure (Pimm, 2004), or the use of 'hedges' to denote uncertainty (Rowland, 1995).

In both vignettes, students used pronouns 'I' and 'you' extensively as they described procedures for finding the feasible region or locating the point of highest profit. These pronouns seem to indicate ownership over particular solution methods. This ownership is again highlighted when Riley asked his group, “anyone have any other ways?," perhaps emphasizing the value placed in this classroom on a variety of different methods, and individual creativity.

With regards to verb tense, in the first vignette it is notable that Garai begins his description of his method with the past tense, indicating the method is something he has completed. When Riley revoices Garai's strategy, he uses the present tense and the pronoun 'you' which could be interpreted as referring strictly to Garai, or a more impersonal 'you' that could use Garai’s strategy. Riley's revoicing is also an interesting move to note in this context, as revoicing is typically described as a move teacher's make 
to position student thinking and to create space for dialogue in mathematics classrooms (Enyedy et al., 2008; O'Connor \& Michaels, 1993).

If we compare the two vignettes with respect to the use of 'hedges,' it is clear that the second group used more hedges in their talk and displayed a greater degree of uncertainty. This difference highlights the fact that although the two groups were engaged in the same classroom activity, they were in fact working at different tasks: in the first group, students were for the most part presenting information that they considered understood. In vignette 2 , the group positioned themselves as uncertain, and struggled to construct a satisfactory explanation for finding the point of highest profit.

A number of authors have highlighted the distinction between 'exploratory' talk and 'final draft' talk (Barnes, 1976/1992 as discussed in ; Cazden, 1988; Wells, 1999). When students are working through mathematical ideas, a final draft-like, polished version of an explanation is not necessarily ideal. Instead, students may find themselves exploring ideas through their talk, and collaboratively constructing new ideas.

Another approach to analysis would be to take a broad view of the phenomenon of explanation, and consider how well the explanations matched the teacher's professed goals that student explanations be relatively complete and coherent with little teacher input. These goals match the goals of the teacher in a study by Hufferd-Ackles, Fuson and Sherin (2004) in which they characterized a range of explanation types (from Level 0 - very little student explanation, to Level 1 - little student explanation, heavy prompting from the teacher for more detail, to Level 2 - prompting from teacher elicits detailed explanations from students, to Level 3 - complete and coherent explanations from students, with little probing from teacher) and showed how students and teachers in one 
U.S.-based Grade 3 mathematics classroom moved from mostly Level 0 explanations to mostly Level 3 explanations over the course of a year.

If this type of analysis were applied to the two vignettes, we might find that in the first vignette, the group practiced mainly a 'Level 2' or perhaps 'Level 3' form of explanation, in which students "stake a position and articulate more information in response to probes" (Hufferd-Ackles et al., 2004, p. 89) or "defend and justify their answers with little prompting from the teacher" (p. 90, italics in original). By contrast, in vignette 2, after deciding they were not sure of their explanation, the group provided "minimal volunteering of thoughts" (p. 89) and were therefore practicing Level 1 explanations. When the teacher came over, Noreen gave a Level 3 explanation in which she defended her solution without any questioning from the teacher. Clearly, these analytic levels were created to describe whole-class discussions orchestrated by a teacher, and are less relevant for small group discussions where a teacher is not always present. A similar framework could be constructed to describe explanations in peer discussions, but would still gloss over the fact that at this point in the year, groups gave a range of different levels of explanation, sometimes within the same activity.

The distinction between sociomathematical norms for explanations in whole class discussion, and those for peer discussions, is an important one. It remains an open question whether and when students in peer discussion would readily adopt the sociomathematical norms associated with whole class discussions. Webb, Nemer and Ing (2006) demonstrated that at least in some classrooms, students readily adopt the discourse practices that their teachers routinely use. The classroom in their study was fairly traditional and teacher-centered; discourse practices were primarily question-answer 
sequences led by the teacher, and evaluated by the teacher. Studies that have demonstrated that students can develop proficiency in the discourse practices common in more student-centered or discussion-based classrooms have focused data collection primarily on whole class discussions, leaving open the question of how students talk with one another without the teacher present (Herbel-Eisenmann et al., 2006; Hufferd-Ackles et al., 2004).

Thus, while these discursive approaches can illuminate important facets of classroom discussions, the vignettes show that explanation practices may be highly situational. Therefore, the context of talk should be taken into account in any analysis of this nature. For example, explanations in the presence of the teacher may differ from explanations made to other students, or explanations may vary depending on student perceptions of the task itself, or their perceived level of understanding of the mathematical material. In the first vignette, when students generally agreed that they understood the material and that their task was to rehearse explanations they could give later, they constructed several detailed explanations, co-authored by multiple students. In the second vignette, the group began by explaining their thinking, but when they collectively decided that they could not solve the problem on their own, they waited for the teacher. When one student indicated that he needed help, he was denied an explanation of what the group had done previously. Later, when the teacher arrived, one of the students who had professed confusion and refused to explain to the group gave a complete explanation for the teacher to confirm. Thus, in addition to considering general characteristics of explanations, it is also important to consider the following questions: what do people accomplish through explanations? And how does their talk support 
mathematical learning? In the following sections, I explore these questions in further detail.

\section{Reconsidering discourse: hybridity, positioning, and talk as a tool for social action}

Peer discussions in schools form a hybrid space, including the official school discourse, and one or more unofficial discourses that students draw on more informally (Gutiérrez, Baquedano-López, \& Tejeda, 1999). While some versions of discourse analysis focus mainly on the talk itself, in such hybrid spaces, James Gee's discussion of connections between identity and discourse is particularly useful (Gee, 1996, 2000).

Gee defines a Discourse (with a capital 'D') as a "socially accepted association among ways of using language, of thinking, feeling, believing, valuing, and of acting that can be used to identify oneself as a member of a socially meaningful group or 'social network', or to signal (that one is playing) a socially meaningful 'role' " (Gee, 1996, p. 143). I will use the term 'discourse practice' to refer to a particular type of talk or social action associated with a Discourse. The significance of this particular definition of Discourse (and discourse analysis) is that identities are made central to the analysis. The decisions that students make about when to speak and which discourses to employ are thus fraught with import, as their talk inevitably positions them as a kind of person in the classroom and in the world. Such classroom spaces are far from neutral, as the classroom's 'official' discourse, and the various home or community discourses that students bring, are not all equally valued (Gutiérrez et al., 1999).

In the vignettes of the jigsaw activity, Ms. Delack had specific expectations for student discourse - expectations that differed significantly from common conversational discourse practices, or even discourse practices that are common in many school settings. 
She expected students to explain their thinking in detail, even if everyone already understood the material (e.g., the first vignette), or if the explainer did not understand it (e.g., Candie in the first vignette).

These practices may contrast with explanation practices in informal conversations. Although students may all have different primary Discourses, and thus perhaps different expectations for talk amongst peers, research on informal conversation has highlighted some ways in which sociomathematical norms for explanation may differ from norms in other Discourses. Conversation analytic research in this area has emphasized that speakers and listeners operate with a substantial body of information that is taken-as-shared (Garfinkel, 1984). Garfinkel points out that to ask for or to give an explanation for an ordinary or common-sense statement is usually considered inappropriate. For example, a seemingly straightforward comment like "it's sunny today" would rarely be greeted with a response like "can you explain what you mean by that?," (although that response may be appropriate in some contexts). Indeed, Garfinkel points out that when this assumption of taken-as-shared is breached, feeling of confusion, anger and anxiety can quickly mount.

That is not to say, of course, that explanations are not routinely offered. In informal conversations, explanations are offered when the validity of a statement is called into question. For example, if the speaker knows something that the hearers do not, or perhaps the speaker and audience disagree, an explanation might be offered (Pomerantz, 1984). If these conversational norms were carried into mathematics classrooms, we should expect explanations when a) the explainer is explaining some new information to listeners, or b) there is a disagreement in the group. Students might consider it 
inappropriate, even rude, to provide detailed explanations in other situations.

Given the above, there are a number of reasons why a student might choose (not) to give an explanation in mathematics class. First of all, a student might, rightly or wrongly, consider an explanation unnecessary because of a common ground of understanding with their peers. For example, in vignette 1, Garai mentioned 'plotting points' without going into detail. The concept of plotting points was taken-as-shared in the group and did not require an explanation. (This does not mean that everyone in the group understood, just that the group acted as if 'plotting points' did not need an explanation at that time.) Every time students begin an explanation, they must decide how much detail to provide.

Secondly, students might not explain if an acceptable explanation had already been given, and they had no new information to add. This could be a problem in some mathematics classrooms, in which it is common practice to ask students to find multiple solution strategies for a single problem. This practice is certainly not a part of most traditional mathematics classrooms, nor does it seem to be a part of most 'everyday' conversations. However, in the first episode, the group rehearsed a number of different explanations. Recall the group's early decision that their job was not to 'understand' the problem. Rather, their job was to explain and to rehearse explanations to give to their peers. The structure of the jigsaw activity allowed students to give detailed explanations to one another without causing offense, or implying that someone did not understand the problem.

Finally, conversational norms can be used as resources for social action and do not need to be followed to the letter. In his book Studies in the way of words, Paul Grice 
(1989) elaborates on a set of maxims that he says govern much of face-to-face conversation. These maxims, such as "make your contribution as informative as is required," and "do not make your contribution more informative than is required" (p. 26) are expansions of Grice's overarching Cooperative Principle: with every conversational move, people are assumed to be cooperating to communicate relevant information. Grice goes on to show how breaches of a maxim are often interpreted as displaying allegiance to the overarching Cooperative Principle. To provide an example taken from the vignettes, Noreen's failure to elaborate on her explanation to Daniel in vignette 2 would be interpreted as providing as much information, and no more than required. Since she chose not to elaborate when asked, her conversational move implies that she had no more information to share.

Of course, later in the vignette, when the teacher arrived at the group, Noreen did provide a more detailed explanation. If she had this information, why did she not share it with Daniel earlier? Although there are many possible reasons, and no way to definitively decide, it is telling that Noreen's conversational move served to align her position with that of Daniel. When he expressed confusion, and she responded simply with a sympathetic 'yeah' and a gesture similar to throwing up her hands in defeat, she positioned them as 'in the same boat.' Her utterance did not accord with various social and sociomathematical norms of the classroom - providing detailed, complete explanations, answering questions from a peer - but served to position her as incapable of fulfilling those norms, not unwilling. The effect is that she is positioned as an ally of Daniel's, and not an antagonist (as she might at first seem, from her blunt refusal to help). 


\section{Reconsidering 'complete' explanations}

So far I have discussed the presence of hybrid language practices within the classroom, and suggested contextual reasons why students who are mathematically knowledgeable, and proficient in classroom sociomathematical norms, still might not provide 'complete' explanations, unprompted by input from other students or from the teacher. In addition, I argue that complete and fluent explanations in mathematics classrooms may not always be the most effective at engaging students in mathematical discourse. If learning mathematics is learning the discourse of mathematics, then it is certainly critically important that students develop facility with 'level 3' explanations. However, one of the key distinguishing factors between Hufferd-Ackles et al.'s level 1 and level 3 explanations is the amount of 'prompting' needed from a teacher. It is not necessarily the case that self-contained and detailed explanations are always the best choice for an oral explanation.

Indeed, Barron (2003) has made a compelling argument that what separates successful groups from less successful groups is their degree of joint attention and engagement with a problem. Barron's findings are supported by research on everyday talk, highlighting how people use a number of conversational techniques to find 'just the right amount' of detail (in accordance with Grice's (1989) maxims). For example, in casual conversation, it is customary to state assertions as simply facts at first, and then in the face of a challenge or doubt, to begin to provide a basis for the claim (Pomerantz, 1984).

This type of back-and-forth talk highlights the active participation of the listener in the speaker's construction of an explanation. As illustration, consider the following 
group interaction, taken from a paper of Noreen Webb and Ann Mastergeorge (2003). In

Excerpt 3, two students are discussing a fairly routine math problem with a goal of

finding the total cost of a long-distance call.

\section{Excerpt 3. Joint attention to an explanation}

Problem 1: Find the cost of a 5-minute telephone call to prefix 756 (first minute costs $\$ 0.19$; each additional minute costs $\$ 0.12$ ).

1 A3: I got 79. [On his paper appear the calculations $12 \times 5+19$.]

2 A1: No, it's 12 times 4.

3 A3: Where'd you get 4 at?

4 A1: 4 minutes and the additional minute is 19 cents. I got 0.67 .

5 A3: 5 minute call, enn... Where'd you get 4 ?

6 A1: Look, look. OK, 12 times 4, right? And then the minute, that's the 19 cents is

the extra minute, which makes it 5.

7 A3: Ah-ha.

8 A1: Because it says after each additional minute, so that means it will be 12 times 4 .

And then you add 19 cents, which is the additional time. You put 12 times 4.

9 A3: Times 4.

10 A1: And then you get the answer, and then you add 19 cents.

11 A3: Oh boy. Now I get it. Smart! Too smart.

(Webb \& Mastergeorge, 2003, p. 390)

In this excerpt, student $\mathrm{A} 3$ begins by making an unsupported assertion, to which

Student A1 disagrees. Over the next several turns, A3 repeatedly asks for clarification, and A1 provides increasingly specific response. In closing, at turn 11, student A3 seems pleased to 'get it,' and also positions student A1 as 'smart.' Some might argue that this interaction was less than ideal because no single turn at talk provided enough information to resolve the difficulty, and student A3 repeatedly requested more information from A1. However, I would argue that this exchange represents concerted joint attention, through a series of conversational repairs. At every turn, A1 and A3 provided one another with a small amount of information, were able to check for understanding, and repair as needed. 
Rather than a full explanation by either person alone, both students actively participated in the resolution of this problem. Their interaction is reminiscent of conversation analytic accounts of story-telling, in which one person serves as the narrator but uses a number of discursive devices to remain aligned with their audience, and to check understanding frequently (Hutchby \& Wooffitt, 2008). This joint construction of the full explanation is significant, especially in light of studies that suggest that students often do not align their explanations to the needs of their audience (Ross, Haimes, \& Hogaboam-Gray, 1996). Seemingly less fluent explanations might actually play an important role in supporting students' mathematical learning, if the students involved maintain joint attention and work to achieve some sense of intersubjectivity.

Of course, students (and others) do not always respond productively to prompts for more information, as we saw in Vignette 2 when Daniel queried Noreen, who chose not to elaborate on her terse explanation. If students are to negotiate a 'detailed enough' explanation together, then both parties have to actively orient to one another's communicative needs. Vignette 2 reminds us that this is not always the case in mathematics classrooms.

\section{Discussion}

Although discourse analysis is becoming widely used in mathematics education research, in this paper I have argued that it is still common for researchers to focus on the content of mathematical talk, without considering the interactional context in which talk occurs. In mathematics classrooms characterized by hybridity, in which students must choose between competing discourse practices around explaining, their choices position students as certain kinds of people within the classroom (Gee, 2000). Analysis that 
focuses on the characteristics of talk will not be able to address some critical questions related to mathematical discourse and learning: what social actions do students perform through allegiance to or breaches of sociomathematical norms? How do these social actions support their identities as mathematics learners, and how does their talk (of all forms) support mathematics learning?

Mathematical discourse practices around explaining are distinctive in that mathematics teachers often encourage students to give lengthy, detailed explanations even when their peers already 'get it,' and even when the explainer is unsure of his or her ideas. While it is possible to structure activities, like the jigsaw activity, to support students' engagement with explaining in these ways, the two vignettes that were discussed at length in this paper demonstrate that simply setting up such an activity may not be enough to help students do so.

A discourse analytic approach can highlight students' competence at various forms of discourse, and the implications for student identity of engaging in various forms of talk. The creation of a set of levels to describe mathematical discourse practices can be helpful as a way to be explicit about teachers' and researchers' goals for mathematical discourse, but should not be used as the only way to analyse students' participation. Otherwise, teachers and researchers may miss the important ways in which non-standard explanation forms might actually support student engagement in mathematical discourse practices. Since explaining plays such a central role in reform mathematics classrooms, it behooves educators and researchers to understand more clearly what kinds of explanations support student learning, rather than only looking at explanations as displays of student learning (Wells, 1999). 
It becomes even more important to consider how students use these sociomathematical and other discourse norms for social action when we consider issues of equity that arise in diverse classrooms. For students whose primary Discourses are compatible with those of the school, adopting an 'official' discourse in a peer discussion proves no problem; for students whose primary Discourses have been marginalized and devalued by school Discourses, this adoption would create a sense of conflict. Gee (1996) describes this conflict in the context of law school as "between who I am summoned to be in this new Discourse (law school) and who I am in other Discourses that overtly conflict with - and sometimes have historically contested with - this Discourse" (p. 135). As Gutierrez et al. point out, the power of hybrid classrooms is that teachers can caplitalize on what they call the 'third space' in between the formal and informal discourse practices. If we as researchers focus only on the value of complete, coherent explanations without input from peers, we will miss some valuable learning moments, and end up reifying those discourse practices that are most closely aligned with the teacher's or researcher's values. 


\section{References}

Andrews, R. (2005). Models of argumentation in educational discourse. Text, 25(1), 107 127.

Barnes, D. (1976/1992). From communication to curriculum. Harmondsworth, UK: Penguin.

Barron, B. (2003). When smart groups fail. Journal of the Learning Sciences, 12(3), 307359.

Barwell, R. (2005). Integrating language and content: Issues from the mathematics classroom. Linguistics and Education, 16(2), 205-218.

Cazden, C. B. (1988). Classroom discourse: The language of teaching and learning. Portsmouth, NH: Heinemann Educational Books.

Clarke, J. (1994). Pieces of the puzzle: The jigsaw method. In S. Sharan (Ed.), Handbook of cooperative learning methods (pp. 34-50). Westport, CT: Greenwood Press.

Enyedy, N., Rubel, L., Castellón, V., Mukhopadhyay, S., Esmonde, I., \& Secada, W. (2008). Revoicing in a multilingual classroom. Mathematical Thinking and Learning, 10(1), 1-29.

Esmonde, I. (2006). "How are we supposed to, like, learn it, if none of us know?": Opportunities to learn and equity in mathematics cooperative learning structures. Unpublished doctoral dissertation, University of California, Berkeley.

Esmonde, I. (In press). Mathematics learning in groups: Analysing equity in two cooperative activity structures. Journal of the Learning Sciences.

Forman, E. A., McCormick, D. E., \& Donato, R. (1998). Learning what counts as a mathematical explanation. Linguistics and Education, 9(4), 313-339.

Garfinkel, H. (1984). Studies in Ethnomethodology. Englewood Cliffs, NJ: Prentice-Hall Inc.

Gee, J. P. (1996). Social linguistics and literacies: Ideology in discourses (2nd ed.). London; Bristol, PA: Taylor \& Francis.

Gee, J. P. (2000). Identity as an Analytic Lens for Research in Education. Review of Research in Education, 25, 99-125.

Grice, H. P. (1989). Studies in the way of words. Cambridge, Massachusetts: Harvard University Press.

Gutiérrez, K. D., Baquedano-López, P., \& Tejeda, C. (1999). Rethinking diversity: Hybridity and hybrid language practices in the third space. Mind, Culture, and Activity, 6(4), 286-303.

Herbel-Eisenmann, B., Lubienski, S. T., \& Id-Deen, L. (2006). Reconsidering the study of mathematics instructional practices: The importance of curricular context in understanding local and global teacher change. Journal of Mathematics Teacher Education, 9, 313-345.

Hufferd-Ackles, K., Fuson, K. C., \& Sherin, M. G. (2004). Describing levels and components of a math-talk learning community. Journal for Research in Mathematics Education, 35(2), 81-116.

Hutchby, I., \& Wooffitt, R. (2008). Conversation analysis (Second ed.). Cambridge, UK: Polity Press. 
Inglis, M., Mejia-Ramos, J. P., \& Simpson, A. (2007). Modelling mathematical argumentation: The importance of qualification. Educational Studies in Mathematics, 66(1), 3-21.

Mendez, E. P., Sherin, M. G., \& Louis, D. A. (2007). Multiple perspectives on the development of an eight-grade mathematical discourse community. The Elementary School Journal, 108(1), 41-61.

Morgan, C. (1998). Writing mathematically: The discourse of investigation. New York: Routledge.

Moschkovich, J. (2002). A situated and sociocultural perspective on bilingual mathematics learners. Mathematical Thinking and Learning, 4(2-3), 189-212.

National Council of Teachers of Mathematics. (2000). Principles and Standards for School Mathematics. Reston, VA: NCTM.

O'Connor, M. C., \& Michaels, S. (1993). Aligning academic task and participation status through revoicing: Analysis of a classroom discourse strategy. Anthropology and Education Quarterly, 24(4), 318-335.

Pimm, D. (2004). Discourse analysis and mathematics education: An anniversary of sorts. Paper presented at the International Congress of Mathematics Education.

Pomerantz, A. M. (1984). Giving a source or basis: The practice in conversation of telling 'how I know'. Journal of Pragmatics, 8, 607-625.

Ross, J. A., Haimes, D. H., \& Hogaboam-Gray, A. (1996). Improving student helpfulness in cooperative learning groups. Journal of Classroom Interaction, 31(2), 13-22.

Rowland, T. (1995). Hedges in mathematics talk: Linguistic pointers to uncertainty. Educational Studies in Mathematics, 29, 327-353.

Sfard, A. (2001). There is more to discourse than meets the ears: Looking at thinking as communicating to learn more about mathematical learning. Educational Studies in Mathematics, 46, 13-57.

Toulmin, S. E. (1958). The uses of argument. Cambridge: Cambridge University Press.

Webb, N. M., \& Mastergeorge, A. M. (2003). The development of students' helping behavior and learning in peer-directed small groups. Cognition and Instruction, 21(4), 361-428.

Webb, N. M., Nemer, K. M., \& Ing, M. M. (2006). Small-group reflections: Parallels between teacher discourse and student behavior in peer-directed groups. The Journal of the Learning Sciences, 15(1), 63-119.

Wells, G. (1999). Dialogic inquiry: Towards a sociocultural practice and theory of education. Cambridge: Cambridge University Press .

Yackel, E., \& Cobb, P. (1996). Sociomathematical norms, argumentation, and autonomy in mathematics. Journal for Research in Mathematics Education, 27(4), 458-477. 


\section{Author Note}

This work was supported by the National Science Foundation under Grant No. ESI0119732 to the Diversity in Mathematics Education Center for Learning and Teaching, a Graduate Student Fellowship from the Institute for Human Development at the University of California, Berkeley, and a Connaught Grant from the University of Toronto. Any opinions, findings, and conclusions or recommendations expressed in this material are those of the author(s) and do not necessarily reflect the position, policy, or endorsement of the funding agencies.

I would like to thank Mariana Levin, Shiuli Mukhopadhyay, Jennifer LangerOsuna, Roland S. Coloma, Joseph Flessa, Ruben Gaztambide-Fernandez, Lance McCready, and editors and anonymous reviewers of the Canadian Journal for Science, Mathematics and Technology Education for their critical feedback on earlier versions of the paper.

Correspondence concerning this article should be addressed to Indigo Esmonde, Ontario Institute for Studies in Education, 252 Bloor St. W., Toronto ON, M5S 1V6, CANADA. Electronic mail may be sent to iesmonde@oise.utoronto.ca. 


\section{Footnotes}

1. Linear programming problems in two variables include a set of constraints on the variables, and a quantity to be maximized or minimized. In the jigsaw activity, this group was supposed to provide general guidelines for finding the feasible region of any linear programming problem. This can be done by first graphing the set of constraints (linear inequalities) and then determining the region of the coordinate plane that satisfies all of the constraints.

2. To find the point(s) of highest profit for a two-variable linear programming problem, students could graph a set of 'profit lines.' This can be done by setting the profit equal to some (arbitrary) value and graphing the resulting line. If one does this repeatedly for different values, one will obtain a set of parallel lines. Students could then visually determine where the line of highest profit would cross the feasible region - always at a boundary point or line for the feasible region. 